\title{
Long-term adverse outcomes associated with drug-eluting stents and bare-metal stent in patients with small coronary artery disease: a systematic review and meta-analysis.
}

\author{
Nabin Chaudhary ${ }^{1}$, Pravesh Kumar Bundhun ${ }^{2}$, Sujan Shrestha ${ }^{1}, \mathrm{He} \mathrm{Yan}^{2}$
}

${ }^{1}$ Department of Cardiology, Grande International Hospital, Dhapasi, Kathmandu, Nepal.

${ }^{2}$ Department of Geriatrics Cardiology, First Affiliated Hospital of Guangxi Medical University, Nanning, Guangxi, P.R. China.

Corresponding Author: Nabin Chaudhary

Department of Cardiology, Grande International Hospital, Dhapasi, Kathmandu, Nepal.

Email: nabin.ch@gmail.com

Funding/Conflict of Interest: The authors have no funding and conflicts of interest to disclose.

\section{Abstract}

Objective: The main purpose of this meta-analysis was to compare the long-term adverse outcomes associated with drug-eluting stents (DES) and bare-metal stent (BMS) in patients with small coronary artery disease (CAD).

Method: Randomized Controlled Trials (RCTs) and observational studies comparing the adverse outcomes such as mortality, major adverse cardiovascular events (MACE), myocardial infarction (MI), stent thrombosis (ST), target lesion revascularization (TLR), target vessel revascularization (TVR), and restenosis in small CAD patients receiving DES and BMS were searched from Embase, PubMed, and Cochrane Library databases. Odds ratios (ORs) with $95 \%$ confidence intervals (CIs) were calculated and the pooled analyses were performed with RevMan 5.3.

Result: A total number of 4,106 patients with small CAD (2,123 patients received DES and 1,983 patients received BMS) have been included in this meta-analysis. Pool-analysis demonstrated that the risk of mortality, MACE, MI, ST, TLR, TVR, and restenosis were significantly lower in DES group, with OR 0.77(95\%CI 0.59-0.99, $\mathrm{P}=0.04$ ), 0.48(95\%CI 0.41-0.56, P<0.00001), 0.74(95\%CI 0.55-0.98, P=0.04), 0.51(95\%CI: 0.26-0.98, P=0.04), 0.24(95\%CI: $0.16-0.37, \mathrm{P}<0.00001$ ), 0.47(95\%CI: 0.38-0.59, $\mathrm{P}<0.00001$ ), and 0.24 (95\% CI 0.14-0.43, $\mathrm{P}<0.00001$ ), respectively.

Conclusion: Compared with BMS, DES had lower rates of adverse clinical outcomes, and restenosis during long-term follow-up.

Keywords: bare metal stent; drug-eluting stents; meta-analysis; percutaneous coronary intervention; small coronary artery

DOI: http://dx.doi.org/10.3126/njh.v15i1.19703

\section{Introduction}

Small coronary arteries are (variably) defined as having a reference vessel diameter (RVD) of $<3.0 \mathrm{~mm} .{ }^{1,2}$ It is estimated that approximately $20-30 \%$ of patients with symptomatic coronary artery disease (CAD) have small vessel CAD. ${ }^{3}$ For small $\mathrm{CAD}$ myocardial revascularization remains a challenge in daily practice for interventional cardiologists. Revascularization by means of percutaneous coronary interventions (PCI) or coronary artery bypass grafts (CABG) is indicated when medical therapy fails to improve the patients' symptom burden. However, CABG in this group of patients is limited by high rates of graft failure ${ }^{4}$ whereas PCI are associated with increased risks of restenosis and adverse clinical outcomes. ${ }^{5}$

PCI with drug eluting stents (DES) reduce restenosis rate by preventing vessel wall recoil and restraining neointimal growth. ${ }^{6}$ However, they are associated with many serious complications like late stent thrombosis, non-homogenous drug delivery and delayed vascularization, which makes bare metal stent (BMS) preferred with shorter dual antiplatelet therapy in patients at high bleeding risk. ${ }^{78}$ A previously published metaanalysis ${ }^{9}$ comparing DES and BMS in small coronary vessels showed lower rate of major adverse cardiovascular events, but no differences were observed in mortality, myocardial infarction and stent thrombosis. In their study among 12 included trials only two studies had a long-term follow-up. Since then several studies were published comparing long-term adverse events associated with DES and BMS in patients with small vessel. ${ }^{10-14}$ However, single studies were underpowered for clinical end-points and only pooled analyses of data from multiple studies can help to clarifying the long-term issue.

Therefore, we performed a systematical review and metaanalysis to evaluate the long-term adverse cardiovascular outcomes between DES and BMS treated patients with small CAD. 


\section{Methods}

Data Sources and Search Strategy

We have searched EMBASE, PubMed and Cochrane Library databases for relevant studies comparing the long-term adverse outcomes associated with DES and BMS in small CAD patients by typing the words 'drug-eluting stents, bare-metal stent, percutaneous coronary intervention, small coronary artery, and small vessel disease'. To further enhance this search, the abbreviations 'DES, BMS, PCI, and small CAD' have also been used. References have also been checked for relevant studies. No language restriction was applied.

\section{Inclusion and Exclusion Criteria}

Studies were included if:

1. They were randomized controlled trials (RCTs) or observational studies dealing with small $C A D(<3 \mathrm{~mm})$ patients.

2. They compared DES with BMS.

3. Adverse outcomes were reported in these patients.

4. They had a mean follow-up period of $\geq 12$ months after stents implantation.

\section{Studies were excluded if:}

1. Adverse outcomes were not reported among their clinical endpoints.

2. They did not include patients with small CAD.

3. They were case studies, meta-analyses or letter to editors.

4. They have not compared DES with BMS.

5. They had follow-up period of $<12$ months.

6. They were duplicates.

\section{Outcomes and Follow-up Periods}

Adverse clinical outcomes analyzed included:

a. Major adverse cardiovascular events

b. Mortality

c. Myocardial infarction

d. Stent thrombosis

e. Target lesion revascularization

f. Target vessel revascularization

g. Restenosis

The Long-term follow-up period was defined as a follow up at $\geq 12$ months. The analyzed clinical adverse outcomes and follow-up periods have been represented in Table 1 .

Table 1. Baseline characteristics, Numbers of DES and BMS implanted patients, endpoints and with their corresponding followup periods.

\begin{tabular}{|c|c|c|c|c|c|c|c|c|c|c|c|}
\hline \multirow[t]{2}{*}{ Author } & \multirow[t]{2}{*}{ Design } & \multicolumn{2}{|c|}{ Study population } & \multirow{2}{*}{$\begin{array}{l}\text { Age (year) } \\
\text { DES/ } \\
\text { BMS }\end{array}$} & \multirow{2}{*}{$\begin{array}{l}\text { Male (\%) } \\
\text { DES/BMS }\end{array}$} & \multirow{2}{*}{$\begin{array}{l}\text { HTN (\%) } \\
\text { DES/BMS }\end{array}$} & \multirow{2}{*}{$\begin{array}{l}\text { DM (\%) } \\
\text { DES/BMS }\end{array}$} & \multirow{2}{*}{$\begin{array}{l}\text { HL (\%) } \\
\text { DES/ } \\
\text { BMS }\end{array}$} & \multirow{2}{*}{$\begin{array}{l}\text { Outcomes } \\
\text { analyzed }\end{array}$} & \multirow{2}{*}{$\begin{array}{l}\text { Types of } \\
\text { DES used }\end{array}$} & \multirow[t]{2}{*}{ Follow-up } \\
\hline & & DES & BMS & & & & & & & & \\
\hline $\begin{array}{l}\text { Jimenez- } \\
\text { Quevedo } \\
2006\end{array}$ & OS & 42 & 43 & $65.1 / 68.3$ & $54.8 / 62.8$ & $73.8 / 67.4$ & $100 / 100$ & $57.1 / 55.8$ & $\begin{array}{l}\text { Mortality, } \\
\text { MACE, MI, } \\
\text { ST,TLR }\end{array}$ & SES & $12 \mathrm{~m}$ \\
\hline Chan 2008 & RCT & 54 & 29 & $58.7 / 62.5$ & $69 / 66$ & $66.7 / 75.9$ & $100 / 100$ & $76.9 / 71.4$ & $\begin{array}{l}\text { Mortality, } \\
\text { MACE, MI, } \\
\text { ST, TLR, } \\
\text { TVR }\end{array}$ & SES & $12 \mathrm{~m}$ \\
\hline $\begin{array}{l}\text { Menozzi } \\
2009\end{array}$ & RCT & 129 & 128 & $63.2 / 63.7$ & $76.7 / 66.4$ & $65.1 / 64.3$ & $19.4 / 29.7$ & $61.2 / 64.8$ & $\begin{array}{l}\text { Mortality, } \\
\text { MACE, MI, } \\
\text { ST, TLR }\end{array}$ & SES & $24 m$ \\
\hline Umeda 2009 & OS & 126 & 118 & $67.2 / 66.0$ & $78 / 70$ & $60 / 68$ & $31 / 34$ & $60 / 61$ & $\begin{array}{l}\text { Mortality, } \\
\text { MACE, MI, } \\
\text { ST,TLR }\end{array}$ & SES & $12 \mathrm{~m}$ \\
\hline Pfisterer 2009 & $\mathrm{RCT}$ & 187 & 81 & 66 & 80 & 73 & 22 & 77 & $\begin{array}{l}\text { Mortality, } \\
\text { MACE, ST, } \\
\text { TVR }\end{array}$ & SES, PES & $36 \mathrm{~m}$ \\
\hline Koh 2010 & OS & 305 & 239 & $62 / 62$ & $61 / 64$ & $83 / 78$ & $100 / 100$ & $88 / 87$ & $\begin{array}{l}\text { Mortality, } \\
\text { MACE, MI, } \\
\text { TVR }\end{array}$ & $\begin{array}{l}\text { SES, PES, } \\
\text { EES, ZES }\end{array}$ & $36 \mathrm{~m}$ \\
\hline $\begin{array}{l}\text { Puymirat } \\
2011\end{array}$ & OS & 277 & 368 & $71 / 72$ & $63 / 69$ & $68 / 60$ & $62 / 9^{*}$ & $67 / 66$ & $\begin{array}{l}\text { Mortality, } \\
\text { MACE, MI, } \\
\text { TVR }\end{array}$ & $\begin{array}{l}\text { SES, PES, } \\
\text { EES, ZES }\end{array}$ & $36 \mathrm{~m}$ \\
\hline Parikh 2011 & OS & 775 & 765 & $63.3 / 63.9$ & $64.4 / 53.4^{*}$ & $78.0 / 69.3^{*}$ & $37.8 / 30.2^{*}$ & $78.1 / 68.7^{*}$ & $\begin{array}{l}\text { Mortality, } \\
\text { MACE, MI, } \\
\text { TVR }\end{array}$ & $\begin{array}{l}\text { SES, PES, } \\
\text { ZES }\end{array}$ & $12 \mathrm{~m}$ \\
\hline $\begin{array}{l}\text { Puymirat } \\
2013\end{array}$ & OS & 107 & 175 & $81 / 82$ & $58 / 55$ & $74 / 69$ & $62 / 9^{*}$ & $64 / 60$ & $\begin{array}{l}\text { Mortality, } \\
\text { MACE, MI, } \\
\text { TVR }\end{array}$ & $\begin{array}{l}\text { SES, PES, } \\
\text { EES, ZES }\end{array}$ & $42 \mathrm{~m}$ \\
\hline Wang 2016 & OS & 121 & 37 & $72.5 / 72.7$ & $71.1 / 81.1$ & $88.4 / 94.6$ & $60.3 / 54.1$ & $66.9 / 70.6$ & $\begin{array}{l}\text { Mortality, } \\
\text { MACE, MI, } \\
\text { ST, TLR }\end{array}$ & $\begin{array}{l}\text { SES, PES, } \\
\text { EES, ZES }\end{array}$ & $32 \mathrm{~m}$ \\
\hline
\end{tabular}

DES: drug-eluting stents, BMS: bare-metal stent, MACE: major adverse cardiovascular events, MI: myocardial infarction, ST: stent thrombosis, TVR: target vessel revascularization, TLR: target lesion revascularization, SES: sirolimus-eluting stent, PES: paclitaxel-eluting stent, EES: everolimus-eluting Stent, ZES: zotarolimuseluting stent, RCT: randomized controlled trial, OS: observational study, HTN: hypertension DM: diabetes mellitus HL: hyperlipidemia, m: months * P<0.05 


\section{Methodological Quality and Statistical Analysis}

The Preferred Reporting Items for Systematic Reviews and Meta-Analyses (PRISMA) was considered for this meta-analysis. ${ }^{15}$ The Cochrane Q-statistic $(\mathrm{P} \leq 0.05$ was considered significant whereas $\mathrm{P}>0.05$ was considered as statistically insignificant) and I2-statistic were used to assess heterogeneity across the trials. I2 described the percentage of total variation across studies, that is, due to heterogeneity rather than chance. A value of $0 \%$ indicated no heterogeneity, and larger values especially from $50 \%$ and above indicated increasing heterogeneity. If I 2 was $<50 \%$, a fixedeffect model was used. However, if I 2 was $>50 \%$, a random effect model was considered. Publication bias was visually estimated by assessing funnel plots. ${ }^{16,17}$ We calculated the odds ratios (OR) and $95 \%$ confidence intervals (CIs) for categorical variables. The pooled analyses were performed with RevMan 5.3 software.

Since this is a systematic review and meta-analysis, ethical approval was not required.

\section{Data Extraction and Quality Assessment}

Three authors (N.C., P.K.B. and S.S.) independently reviewed the data and assessed the eligibility and methodological quality of each eligible trial. Information regarding the author names, the study type, year of publication, the total number of small CAD patients with stents implantation, the patient characteristics, and the adverse clinical outcomes reported as well as the follow-up periods was systematically extracted. If any of the 3 authors disagreed about the information or data extracted, disagreements were discussed between the authors, and if they could not reach a decision, it was discussed and resolved by the fourth author (H.Y.). The bias risk of trials was assessed with the components recommended by the Cochrane Collaboration. ${ }^{18}$

\section{Results}

\section{Study Selection}

As illustrated in the flow diagram (Fig. 1), 577 articles were identified by title and abstract. After elimination of duplicates, 198 articles were further screened. 160 articles were excluded since they were not related to the title of our study. Thirty eight full-text articles were finally assessed for eligibility of which, 28 were further excluded for several reasons: they were case studies, meta-analyses or letters to the editor, follow-up $<12$ months, in some trials DES treated group was compared with BMS plus drug-eluting balloon treated group. Finally, 10 studies (3 RCTs ${ }^{13,19,20}$ and 7 observational ${ }^{10-12,14,21-23)}$ were selected and included in this study.

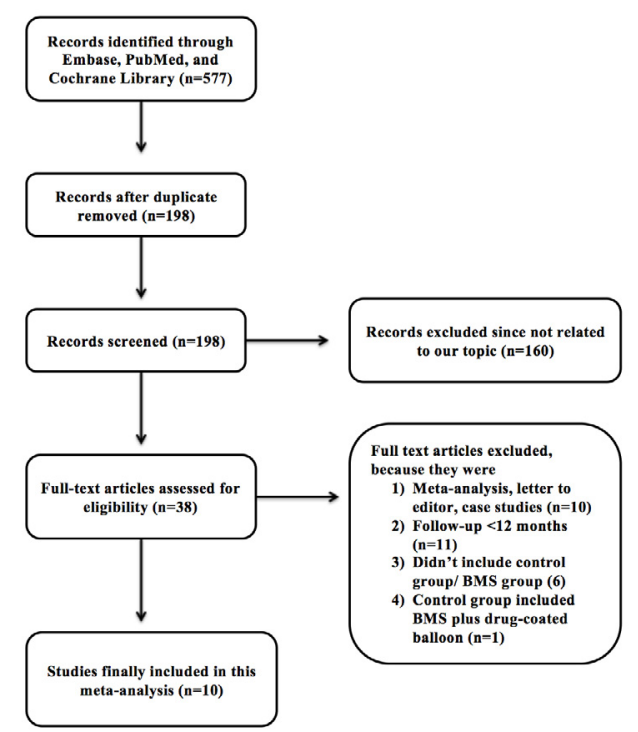

Figure 1. The flow diagram of study selection.

\section{Baseline Characteristics of Included Trials}

These 10 studies which have been included in this systematic review and meta-analysis consisted of a total of 4,106 small CAD patients; among them, 2,123 patients received DES and remaining 1,983 patients received BMS treatment. The baseline characteristics of each included study is shown in Table 2. Data from each study were reported. Publication year, the design of studies, the number of the population involved in DES and BMS group mean age of patients, the percentage of male patients, the percentage of patients with hypertension, diabetes mellitus, dyslipidemia and follow-up periods is listed in Table 1.

In this meta-analysis, the mean follow-up duration ranged from 12-42 months. In 6 studies, ${ }^{10-14,19}$ the follow-up period was $\geq 24$ months. The mean ages of the patients ranged from 62-82 years. Among 9 studies, 1 study $^{12}$ reported that the age of patients was $>80$ years. The percentage of men was $53.4-81.1 \%$. In three studies, ${ }^{10,20,23}$ PCI were done in small CAD patients with diabetes mellitus (DM). Moreover, in another 3 studies, ${ }^{11,12,22}$ the proportion of patients with DM was higher in DES group. In one study, ${ }^{22}$ the proportion of patients with hypertension, hyperlipidemia, and percentage of the male were higher in DES group. In two studies, ${ }^{11,22}$ the proportion of patients with ACS was higher in BMS group.

\section{Main Outcomes of This Meta-analysis}

At a mean follow-up period of 25.4 months, the pooled result of this meta-analysis showed that DES was associated with a significantly lower incidence of the mortality, MACE, MI, ST, TLR, TVR, and restenosis, with (OR 0.77, 95\%CI 0.59-0.99, $\mathrm{P}=0.04, \mathrm{I} 2=0 \%),(\mathrm{OR} 0.48,95 \% \mathrm{CI} 0.41-0.56, \mathrm{P}<0.00001, \mathrm{I} 2=38 \%)$, (OR 0.74, 95\%CI 0.55-0.98, P=0.04, I2=32\%), (OR 0.51, 95\%CI: $0.26-0.98, \mathrm{P}=0.04, \mathrm{I} 2=0$ ), (OR 0.24, $95 \% \mathrm{CI}$ : 0.16-0.37, $\mathrm{P}<0.00001$, I2 $=0 \%$ ), (OR 0.47, 95\%CI: $0.38-0.59, \mathrm{P}<0.00001, \mathrm{I} 2=65 \%)$, and (OR $0.24,95 \%$ CI $0.14-0.43, \mathrm{P}<0.00001, \mathrm{I} 2=0 \%$ ), respectively. The detailed result for all adverse events is shown in Fig. 2.

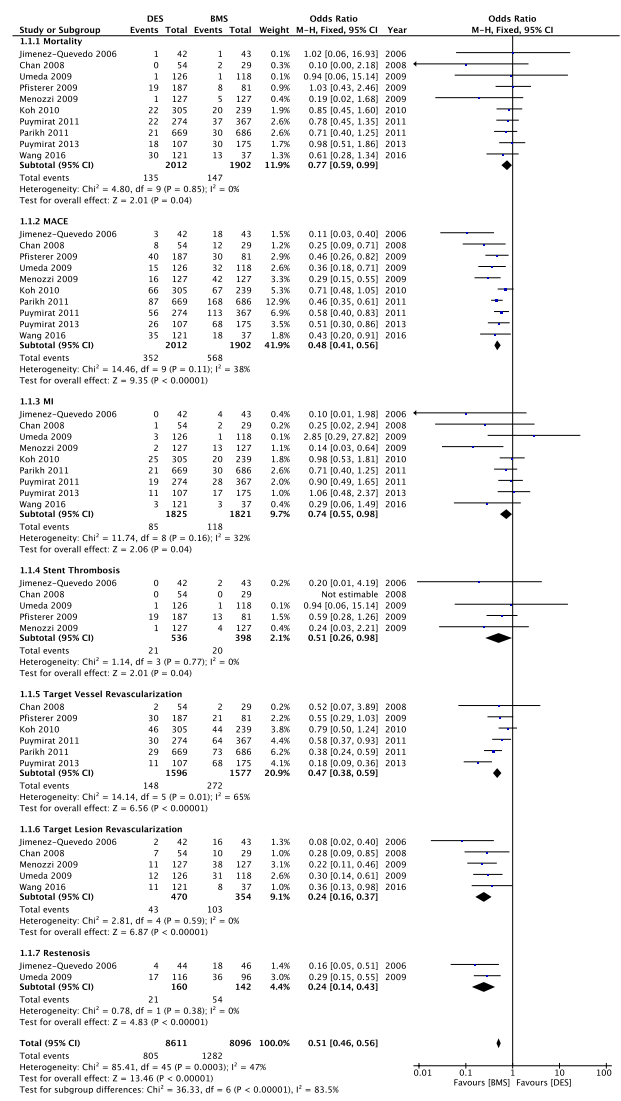

Figure 2. Forest plot showing the odds ratio of mortality, major adverse cardiovascular events (MACEs), myocardial infarction (MI), and stent thrombosis, target vessel revascularization (TVR), target lesion revascularization (TLR), and restenosis associated with drug-eluting stents (DES) versus bare-metal stent (BMS). 
In the subgroup analysis of DM, the risk of MACE, TLR, restenosis were lower in DES group with (OR 0.53, 95\% CI 0.37 $0.74, \mathrm{P}=0.0003, \mathrm{I} 2=80 \%),(\mathrm{OR} 0.17,95 \% \mathrm{CI} 0.07-0.40, \mathrm{P}<0.0001$, $\mathrm{I} 2=38 \%),(\mathrm{OR} 0.16,95 \% \mathrm{CI} 0.05-0.51, \mathrm{P}=0.002)$. However, there was no significant difference in the risk of mortality, MI, ST, and TVR between DES and BMS groups (OR 0.76, 95\% CI $0.42-1.38, \mathrm{P}=0.37, \mathrm{I} 2=0 \%$; OR $0.77,95 \%$ CI $0.44-1.35, \mathrm{P}=0.36$, $\mathrm{I} 2=36$; OR $0.20,95 \%$ CI $0.01-4.19, \mathrm{P}=0.30$; and $\mathrm{OR} 0.77,95 \%$ CI $0.50-1.20, P=0.25, I 2=0$, respectively) as shown in Fig. 3 .

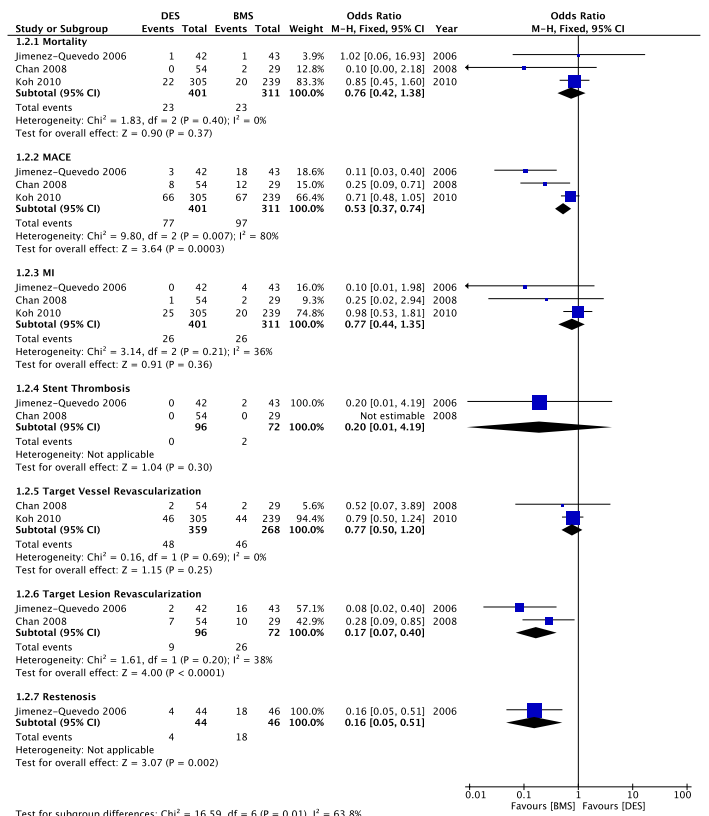

Figure 3. Forest plot showing the odds ratio of mortality, major adverse cardiovascular events (MACEs), myocardial infarction (MI), and stent thrombosis, target vessel revascularization (TVR), target lesion revascularization (TLR), and restenosis associated with drug-eluting stents (DES) versus bare-metal stent (BMS) in diabetes mellitus patients.

For all of the above analyses, sensitivity analysis yielded consistent results. Based on a visual inspection of the funnel plot, there has been no evidence of publication bias for the included studies that assessed the adverse clinical end-points. The funnel plot is shown in Fig. 4.

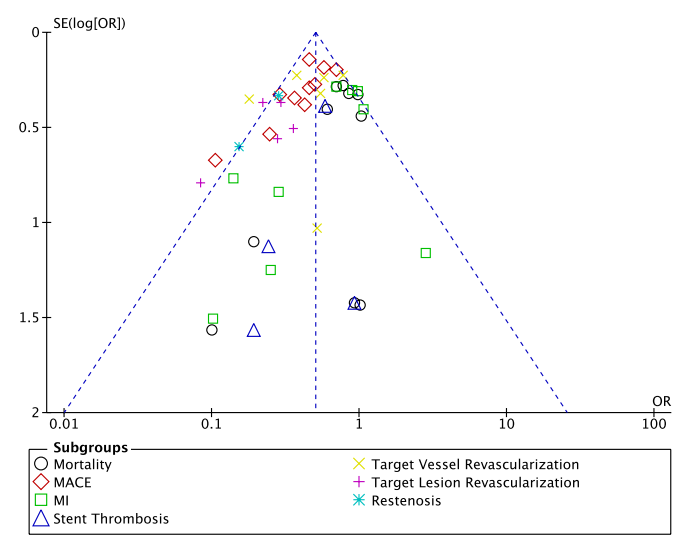

Figure 4. Funnel plot for subgroup analysis.

\section{Discussion:}

This meta-analysis investigates the long-term adverse outcomes of DES versus BMS in patients with small CAD treated with percutaneous revascularization. Our findings showed that DES treated group had a lower risk of mortality, MACE, MI, ST, TVL, TVR and restenosis as compared with BMS treated group at 25.4 months of follow-up. However, in DM subgroup the risk of mortality, MI, ST, and TVR were comparable between DES and BMS groups. The risk of MACE, TLR and restenosis were higher in BMS group compared with DES group in DM subgroup analysis.

Worldwide small coronary artery revascularization by means of PCI represents $30-50 \%$ of the catheter-based coronary interventions per year. ${ }^{5,24,25}$ PCI in small vessel remain a real challenge for the interventional cardiologists in daily practice because of an increased risk of adverse clinical events. ${ }^{1,24-26}$ In large coronary arteries lesion, stenting has become the main method of myocardial revascularization compared with balloon angioplasty in preventing restenosis. ${ }^{27}$ However, conflicting results were reported about efficacy in small coronary arteries. ${ }^{2,26,28}$ Possible explanations for the lack of efficacy of coronary angioplasty in preventing restenosis in small CAD may be associated with the characteristics of patients having atherosclerotic small-vessel lesions, i.e., DM patients, elder patients, women, multi-vessel diseases and patients with the peripheral vascular disease, all of whom are at a higher risk of restenosis. ${ }^{29,30}$ Another reason for decreased efficacy of angioplasty may be related to the small diameter of the vessels, which has been reported a powerful independent predictor of restenosis and repeat revascularization. ${ }^{31}$ This is mainly due to the limited ability of the vessel to accommodate even for limited neointimal proliferation that might develop after stent implantation. To improve the clinical outcomes, DES are increasingly used as a primary angioplasty strategy ${ }^{32,33}$ even in patients with off-label indications. ${ }^{34}$

The analyses of several previous studies at $<12$ months of follow-up showed that the use of DES in small CAD lead to a reduced risk of restenosis and MACE as compared with that of BMS. ${ }^{35-39}$ Moreover, the meta-analysis published by Cortese et $\mathrm{al}^{9}$ comparing DES with BMS in patients with small coronary vessels using data from 12 trials, showed patients receiving DES to have lower rate of TVF ( $11.2 \%$ vs $21.9 \%)$, MACE $(12.5 \%$ vs $26.5 \%$ ), binary restenosis ( $9.7 \%$ vs $36.7 \%$ ) and late lumen loss compared to those patients treated with BMS; in contrast ST, MI, and mortality were not statistically different between studies at mean follow-up period of 12 months. Moreover, recently another comprehensive network meta-analysis published by Siontis et al. ${ }^{40}$ demonstrated that sirolimus eluting stent (SES) is superior to paclitaxel eluting stent (PES), BMS, drug-coated balloons and balloon angioplasty for percutaneous treatment of small vessel CAD. In their study they observed lower TLR, and no differences in mortality and MI in SES group compared with BMS group. Furthermore, a study by Sugihara et al. ${ }^{41}$ comparing DES and BMS in small coronary arteries showed no significant difference in the incidence of MACE including TLR rate, whereas in-stent restenosis in DES were significantly lower compared with BMS treated group. Possible explanations for the difference in the rate of TLR was that in their study they were included more severe lesions concerning minimal lumen diameter and lesion length than other trials. Moreover, ISAR-SMART ${ }^{42}$ (intracoronary stenting or angioplasty for restenosis reduction in small arteries) study showed significantly lower angiographic restenosis and TLR with the use of SES compared with BMS. Additionally, post hoc subanalysis of TAXUS $\mathrm{V}^{43}$ trial demonstrated the clinical outcomes of patients with a mean luminal diameter of $2.08 \mathrm{~mm}$ treated with $2.25 \mathrm{~mm}$ PES. In their study they observed that restenosis rates were significantly less when compared with BMS, although angiographic binary restenosis and TLR still occurred in approximately $20 \%$ and $10 \%$ of patients respectively with DES. Moreover, in sub analysis, there were no significant 
differences in the rates of mortality, MI, and ST at 1 month and 9 months between PES and BMS.

A previous study identified that smaller reference vessel diameter (RVD) known as a predictor of ST. The study by e-CYPHER registry reported that the rates of ST in small vessel and MI were higher than those in larger vessels in DES and BMS treated groups. ${ }^{44,45}$ In our study, the rates of ST and MI were lower in DES group compared with BMS treated group. However, in DM subgroup analysis, ST and MI were comparable between DES and BMS. Generally, patients with DM have more diffuse and smaller vessel disease, and their lesion background may be more severe. The study by Ortolani et al. ${ }^{46}$ comparing DES with BMS in small CAD patients with DM showed that SES had significant decreased risk of angiographic restenosis rate, both in-stent ( $11 \%$ vs $59 \%$; $\mathrm{p}<0.001)$, as well as in-segment $(25 \%$ vs $63 \% ; \mathrm{p}=0.003)$ at 8 months of follow-up period. Moreover, in their study, no clinical differences were observed in the incidence of MACE during follow-up. However, in our meta-analysis during long-term follow-up, in the subgroup analysis of DM, the risk of MACE, TLR, and restenosis were lower in DES group.

In addition, another study by Mezzoni et al. ${ }^{19}$ showed that at 2 years, the incidence of the composite endpoint of mortality, MI, clinically driven TLR, and cerebrovascular accident for SES were lower in compared with BMS. These results are consistent with the present findings.

At last, in our study, patients treated with DES not only reported lower rate of MACE, TLR, and restenosis but also showed lower incidence of mortality, MI, and stent thrombosis. Moreover, our study satisfied all the criteria for a meta-analysis in terms of low level of heterogeneity, low risk of bias and robust results. Therefore, in order to select appropriate revascularization strategies for long-term benefits in patients with small CAD, interventional cardiologists and physicians might take advantages from our study. Additional RCTs with long-term follow-up in a larger number of patients are needed to fully assess the long-term advantages of DES in small coronary arteries.

\section{Limitations:}

The present meta-analysis has several limitations. The articles included in the analysis were mostly non-randomized controlled trials; therefore, there is a possibility of selection bias. Due to the very small number of patients in this study, this analysis may not generate the required or expected results. The follow-up periods were not similar in all the articles. Moreover, among 10 studies, in 3 studies DES and BMS were implanted in small CAD patients with DM, which could limit our results. In addition, percutaneous coronary revascularization by using SES was more than others DES. Out of 10 studies, in 5 studies second generation DES were used, but their adverse outcomes were not demonstrated separately. The best way to answer these shortcomings is a long-term randomized control trial.

\section{Conclusion:}

Compared with BMS, DES had lower rates of MACE, MI, stent thrombosis, TLR, TVR, and restenosis at 25.4 months of follow-up. However, patients treated with a DES had similar risk of mortality compared with BMS in small CAD patients. RCTs with long-term follow-up in a larger number of patients are needed to fully assess the long-term advantages of DES.

\section{Author Contributions}

Conceived and designed the experiments: NC PKB HY. Performed the experiments: NC PKB HY. Analyzed the data:
NC PKB HY. Contributed reagents/materials/ analysis tools: NC PKB SS HY. Wrote the paper: NC.

\section{References:}

1. Agostoni P, Biondi-Zoccai GGL, Gasparini GL, et al. Is bare-metal stenting superior to balloon angioplasty for small vessel coronary artery disease? Evidence from a metaanalysis of randomized trials. Eur Heart J. 2005;26(9):881889. https://doi.org/10.1093/eurheartj/ehi116.

2. Doucet S, Schalij MJ, Vrolix MC, et al. Stent placement to prevent restenosis after angioplasty in small coronary arteries. Circulation. 2001;104(17):2029-2033. http://www. ncbi.nlm.nih.gov/pubmed/11673341.

3. Biondi-Zoccai GGL, Sangiorgi GM, Antoniucci D, et al. Testing prospectively the effectiveness and safety of paclitaxel-eluting stents in over 1000 very high-risk patients: design, baseline characteristics, procedural data and inhospital outcomes of the multicenter Taxus in Real-life Usage Evaluation (TRUE). Int J Cardiol. 2007;117(3):349354. https://doi.org/10.1016/j.ijcard.2006.05.018.

4. O'Connor NJ, Morton JR, Birkmeyer JD, Olmstead EM, O'Connor GT. Effect of coronary artery diameter in patients undergoing coronary bypass surgery. Northern New England Cardiovascular Disease Study Group. Circulation. 1996;93(4):652-655. http://www.ncbi.nlm. nih.gov/pubmed/8640991. https://doi.org/10.1161/01. CIR.93.4.652

5. EleziS,KastratiA,Neumann FJ,HadamitzkyM,Dirschinger J, Schömig A. Vessel size and long-term outcome after coronary stent placement. Circulation. 1998;98(18):18751880. http://www.ncbi.nlm.nih.gov/pubmed/9799207. https://doi.org/10.1161/01.CIR.98.18.1875

6. Kirtane AJ, Gupta A, Iyengar S, et al. Safety and efficacy of drug-eluting and bare metal stents: comprehensive meta-analysis of randomized trials and observational studies. Circulation. 2009;119(25):3198-3206. https://doi. org/10.1161/CIRCULATIONAHA.108.826479.

7. Rymer JA, Harrison RW, Dai D, et al. Trends in BareMetal Stent Use in the United States in Patients Aged $\geq 65$ Years (from the CathPCI Registry). Am J Cardiol. 2016;118(7):959-966.https://doi.org/10.1016/j. amjcard.2016.06.061.

8. Betala J V, Langan Iii EM, LaBerge M. Drug-coated percutaneous balloon catheters. Crit Rev Biomed Eng. 2014;42(3-4):193-212. http://www.ncbi.nlm.nih. gov/pubmed/25597236. https://doi.org/10.1161/01. CIR.98.18.1875

9. Cortese B, Bertoletti A, De Matteis S, Danzi GB, Kastrati A. Drug-eluting stents perform better than bare metal stents in small coronary vessels: a meta-analysis of randomised and observational clinical studies with mid-term follow up. Int J Cardiol. 2012;161(2):73-82. https://doi.org/10.1016/j. ijcard.2011.04.016.

10. Koh AS, Chia S, Choi LM, et al. Long-term outcomes after coronary bare-metal-stent and drug-eluting-stent implantations: a "real-world" comparison among patients with diabetes with diffuse small vessel coronary artery disease. Coron Artery Dis. 2011;22(1):96-99. https://doi. org/10.1097/MCA.0b013e32834236d0.

11. Puymirat E, Mangiacapra F, Peace A, et al. Long-term clinical outcome in patients with small vessel disease treated with drug-eluting versus bare-metal stenting. Am Heart J. 2011;162(5):907-913. https://doi.org/10.1016/j. ahj.2011.07.024.

12. Puymirat E, Mangiacapra F, Peace A, et al. Safety and 
effectiveness of drug-eluting stents versus bare-metal stents in elderly patients with small coronary vessel disease. Arch Cardiovasc Dis. 2013;106(11):554-561. https://doi. org/10.1016/j.acvd.2013.06.056.

13. Pfisterer M, Brunner-La Rocca HP, Rickenbacher P, et al. Long-term benefit-risk balance of drug-eluting vs. bare-metal stents in daily practice: does stent diameter matter? Three-year follow-up of BASKET. Eur Heart J. 2009;30(1):16-24. https://doi.org/10.1093/eurheartj/ ehn516.

14. Wang W-T, Sung S-H, Wu C-H, et al. Long-term outcome of patients with very small coronary artery disease: A comparison of drug-eluting and bare metal stents. J Chin Med Assoc. 2016;79(12):642-648. https://doi. org/10.1016/j.jcma.2016.04.010.

15. Liberati A, Altman DG, Tetzlaff J, et al. The PRISMA statement for reporting systematic reviews and metaanalyses of studies that evaluate healthcare interventions: explanation and elaboration. BMJ. 2009;339:b2700. http:// www.ncbi.nlm.nih.gov/pubmed/19622552. https://doi. org/10.1136/bmi.b2700

16. Riley RD, Higgins JPT, Deeks JJ. Interpretation of random effects meta-analyses. BMJ. 2011;342:d549. http:// www.ncbi.nlm.nih.gov/pubmed/21310794. https://doi. org/10.1136/bmj.d549

17. Higgins JPT, Altman DG. Higgins JPT GS. Assessing risk of bias in included studies. Cochrane Handb Syst Rev Interv. 2008; Wiley:280-282.

18. Higgins JP, Green S. Assessing Risk of Bias in Included Studies. (Higgins JP, Green S, eds.). Chichester, UK: John Wiley \& Sons, Ltd; 2008. https://doi. org/10.1002/9780470712184.

19. Menozzi A, Solinas E, Ortolani P, et al. Twenty-four months clinical outcomes of sirolimus-eluting stents for the treatment of small coronary arteries: the long-term SESSMART clinical study. Eur Heart J. 2009;30(17):20952101. https://doi.org/10.1093/eurheartj/ehp224.

20. Chan C, Zambahari R, Kaul U, et al. A randomized comparison of sirolimus-eluting versus bare metal stents in the treatment of diabetic patients with native coronary artery lesions: the DECODE study. Catheter Cardiovasc Interv.2008;72(5):591-600.https://doi.org/10.1002/ ccd. 21719 .

21. Umeda H, Iwase M, Gochi T, et al. Safety and efficacy of $2.5-\mathrm{mm}$ sirolimus-eluting stent implantation at lower deployment pressures in very small vessels $(<2.5 \mathrm{~mm})$. Coron Artery Dis. 2009;20(2):163-168. https://doi. org/10.1097/MCA.0b013e328329dc20.

22. Parikh S V, Luna M, Selzer F, et al. Outcomes of small coronary artery stenting with bare-metal stents versus drug-eluting stents: results from the NHLBI Dynamic Registry. Catheter Cardiovasc Interv. 2014;83(2):192-200. https://doi.org/10.1002/ccd.23194.

23. Jiménez-Quevedo P, Sabaté M, Angiolillo DJ, et al. [Efficacy of sirolimus-eluting stent implantation in diabetic patients with very small vessels $(<$ or $=2.25 \mathrm{~mm})$. Insights from the DIABETES trial]. Rev Esp Cardiol. 2006;59(10):10001007. http://www.ncbi.nlm.nih.gov/pubmed/17125709. https://doi.org/10.1157/13093976

24. Bourassa MG, Lespérance J, Eastwood C, et al. Clinical, physiologic, anatomic and procedural factors predictive of restenosis after percutaneous transluminal coronary angioplasty. J Am Coll Cardiol. 1991;18(2):368-376. http:// www.ncbi.nlm.nih.gov/pubmed/1856404. https://doi.
org/10.1016/0735-1097(91)90588-Z

25. Hirshfeld JW, Schwartz JS, Jugo R, et al. Restenosis after coronary angioplasty: a multivariate statistical model to relate lesion and procedure variables to restenosis. The M-HEART Investigators. J Am Coll Cardiol. 1991;18(3):647-656. http://www.ncbi.nlm.nih. gov/pubmed/1869725. https://doi.org/10.1016/07351097(91)90783-6

26. Koning R, Eltchaninoff H, Commeau P, et al. Stent placement compared with balloon angioplasty for small coronary arteries: in-hospital and 6-month clinical and angiographic results. Circulation. 2001;104(14):1604-1608. http://www.ncbi.nlm.nih.gov/pubmed/11581136. https:// doi.org/10.1161/hc3901.096695

27. Fischman DL, Leon MB, Baim DS, et al. A randomized comparison of coronary-stent placement and balloon angioplasty in the treatment of coronary artery disease. Stent Restenosis Study Investigators. N Engl J Med. 1994;331(8):496-501. https://doi.org/10.1056/ NEJM199408253310802.

28. Briguori C, Nishida T, Adamian M, et al. Coronary stenting versus balloon angioplasty in small coronary artery with complex lesions. Catheter Cardiovasc Interv.2000;50(4):390-397.http://www.ncbi.nlm.nih.gov/ pubmed/10931606.https://bit.ly/2If5BRg.

29. Al Suwaidi J, Berger PB, Holmes DR. Coronary artery stents. JAMA. 2000;284(14):1828-1836. http://www.ncbi. nlm.nih.gov/pubmed/11025836. https://doi.org/10.1001/ jama.284.14.1828

30. Mehilli J, Kastrati A, Dirschinger J, Bollwein H, Neumann FJ, Schömig A. Differences in prognostic factors and outcomes between women and men undergoing coronary artery stenting. JAMA. 2000;284(14):1799-1805. http:// www.ncbi.nlm.nih.gov/pubmed/11025832. https://doi. org/10.1001/jama.284.14.1799

31. Rathore S, Terashima M, Katoh O, et al. Predictors of angiographic restenosis after drug eluting stents in the coronary arteries: contemporary practice in real world patients. EuroIntervention. 2009;5(3):349-354. http:// www.ncbi.nlm.nih.gov/pubmed/19736160. https://doi. org/10.4244/V5I3A55

32. Morice M-C, Serruys PW, Sousa JE, et al. A randomized comparison of a sirolimus-eluting stent with a standard stent for coronary revascularization. $\mathrm{N}$ Engl J Med. 2002;346(23):1773-1780.https://doi.org/10.1056/ NEJMoa012843.

33. Moses JW, Leon MB, Popma JJ, et al. Sirolimus-eluting stents versus standard stents in patients with stenosis in a native coronary artery. N Engl J Med. 2003;349(14):13151323. https://doi.org/10.1056/NEJMoa035071.

34. Marroquin OC, Selzer F, Mulukutla SR, et al. A comparison of bare-metal and drug-eluting stents for off-label indications. N Engl J Med. 2008;358(4):342-352. https:// doi.org/10.1056/NEJMoa0706258.

35. Meier B, Sousa E, Guagliumi G, et al. Sirolimuseluting coronary stents in small vessels. Am Heart J.2006;151(5):1019.e1-7.https://doi.org/10.1016/j. ahj.2006.02.025.

36. Ortolani P, Ardissino D, Cavallini C, et al. Effect of sirolimus-eluting stent in diabetic patients with small coronary arteries (a SES-SMART substudy). Am J Cardiol. 2005;96(10):1393-1398.https://doi.org/10.1016/j. amjcard.2005.07.049.

37. Schampaert E, Cohen EA, Schlüter M, et al. The Canadian 
study of the sirolimus-eluting stent in the treatment of patients with long de novo lesions in small native coronary arteries (C-SIRIUS). J Am Coll Cardiol. 2004;43(6):11101115. https://doi.org/10.1016/j.jacc.2004.01.024.

38. Schofer J, Schlüter M, Gershlick AH, et al. Sirolimuseluting stents for treatment of patients with long atherosclerotic lesions in small coronary arteries: doubleblind, randomised controlled trial (E-SIRIUS). Lancet (London, England). 2003;362(9390):1093-1099. https:// doi.org/10.1016/S0140-6736(03)14462-5.

39. Ardissino D, Cavallini C, Bramucci E, et al. Sirolimuseluting vs uncoated stents for prevention of restenosis in small coronary arteries: a randomized trial. JAMA. 2004;292(22):2727-2734.https://doi.org/10.1001/ jama.292.22.2727.

40. Siontis GCM, Piccolo R, Praz F, et al. Percutaneous Coronary Interventions for the Treatment of Stenoses in Small Coronary Arteries: A Network Meta-Analysis. JACC Cardiovasc Interv. 2016;9(13):1324-1334. https://doi. org/10.1016/j.jcin.2016.03.025.

41. Sugihara M, Miura S, Nishikawa H, et al. Characteristics of patients and types of lesions in patients with drug-eluting or bare-metal stent implantation in small coronary arteries:

Cite this article as: Nabin Chaudhary, Pravesh Kumar Bundhun, Sujan Shrestha, at.el. Long-term adverse outcomes associated with drug-eluting stents and bare-metal stent in patients with small coronary artery disease: a systematic review and meta-analysis. Nepalese Heart Journal 2018; 15(1): 1-7. http://dx.doi.org/10.3126/njh.v15i1.19703 from the FU-Registry. J Cardiol. 2013;61(2):117-121. https://doi.org/10.1016/j.jjcc.2012.09.008.

42. Mehilli J, Dibra A, Kastrati A, et al. Randomized trial of paclitaxel- and sirolimus-eluting stents in small coronary vessels. Eur Heart J. 2006;27(3):260-266. https://doi. org/10.1093/eurheartj/ehi721.

43. Stone GW, Ellis SG, Cannon L, et al. Comparison of a polymer-based paclitaxel-eluting stent with a bare metal stent in patients with complex coronary artery disease: a randomized controlled trial. JAMA. 2005;294(10):12151223. https://doi.org/10.1001/jama.294.10.1215.

44. Lemos PA, Arampatzis CA, Saia F, et al. Treatment of very small vessels with $2.25-\mathrm{mm}$ diameter sirolimuseluting stents (from the RESEARCH registry). Am J Cardiol. 2004;93(5):633-636. https://doi.org/10.1016/j. amjcard.2003.11.037.

45. Urban P, Gershlick AH, Guagliumi G, et al. Safety of coronary sirolimus-eluting stents in daily clinical practice: one-year follow-up of the e-Cypher registry. Circulation. 2006;113(11):1434-1441. https://doi.org/10.1161/ 